Among numerous subjects which came up for consideration, it appeared that the scheme for publication, in a uniform manner, of actual observations and monthiy results from a limited number of stations in each country, which are to be considered as international, had been already accepted almost without exception or suggestion of amendment by all the countries which had been present at Vienna. It is hoped that this measure will ultimately tend to bring about uniformity in hours and methods of observation.

In weather ielegraphy it was resolved to calculate gradients in the metric scale, as millimetres per one degree (sixty nautical miles). In this country they will be referred to English units. It was not found practicable to endeavour to introduce uniform hours for observations in weather telegraphy in Europe at present. As to weather charts, a proposal for the exclusion of all meridians except that of Greenwich was postponed to the next Congress. It was resolved to take advantage of that meeting to attempt to effect the comparison of the principal standard barometers by means of travelling barometers to be conveyed to the place of meeting, and left there for a considerable time.

It was recognised as impracticable at present to create an International Meteorological Institute, and consequently it was decided that international investigations must be carried on at the expense of individual nations, other nations to be requested to furnish materials, as far as possible, in a usable form. A list of upwards of 200 subscribers to the international synoptic weather charts of Capt. Hoffmeyer was announced.

Resolutions were adopted in favour of the establish ment of stations on high mountains, and in distant localities, and Lieut. Weyprecht's proposition for a circle of observing stations in the Arctic Regions round the Pole was recognised as scientifically of high importance and deserving of general support.

With reference to universal instructions for observations it was stated that no general form of instructions could be drawn up to suit all climates, and it appeared to the committee that the instructions recently prepared in the German, Russian, and English languages respecively, as well as in Italian (as soon as some contemplated modifications shall have been introduced), were sufficiently in accordance with the requirements of the Vienna Congress. It was hoped that ere long French instructions of the same tenor would be issued.

It was announced that the Italian Government was prepared to invite the next Congress to meet at Rome in September I877, and the proposal was most gratefully accepted. In preparation for this mesting a number of reports on the present state of the different departments of the science are called for from various meteorologists. The questions to be treated in these reports are mainly instrumental, and they are of great importance in the present state of the subject. The detailed Report of the Committee will be published without delay.

\section{SOIREE OF THE ROYAL MICROSCOPICAL SOCIETY}

Friday, April 2ist, Mr. H. C. Sorby, president of the Royal Microscopical Society, gave a large soirée in the apartments of King's College. Invitations had been issued for above 1,500 , including the whole of the Fellows of the Royal Microscopical Society, the presidents and leading officers of many of the London Scientific Societies; all the distinguished foreigners now in London as commissioners from the various foreign Governments to the Exhibition of Scientific Apparatus at South Kensington; and many of the President's private friends. About 800 were present, including about 300 ladies. After having been received by the President and one of the secretaries, the visitors passed into the various rooms of the College, in which were exhibited many objects connected with microscopical science. For the number, variety, scientific value, or general interest of the specimens, this exhibition has probably never been surpassed. Amongst the new instruments may be mentioned Mr. Sorby's arrangement for accurately measuring the wave-length of the centre of absorption-bands in spectra; a new form of Stephenson's erecting binocular microscope, by Mr. Bevington, and another by Mr. Browning, of somewhat different construction. Mr. Browning also exhibited his new portable microscope, which is so constructed that the body can be turned on one side and reversed in such a manner as to reduce the height to about one half. The President also exhibited a large series of specimens illustrating his own special subjects, shown by means of fifty microscopes, lent to him by four of the principal makers in London (Becks, Browning, Crouch, and Ross), and about 150 first-rate instruments and objects were contributed by the Fellows of the society and other friends. These were so distributed over the large apartments of the College as to avoid crowding in any part. Almost every branch of science to which the microscope has been applied was well represented, and many of the finest specimens ever prepared were shown and described. Many very interesting living objects were sent direct from the Brighton Aquarium and elsewhere. In the lecture theatre were exhibited Dr. Hudson's most beautiful drawings of microscopic objects shown in a new manner as transparencies; Mr. Spottiswoode's splendid polarising apparatus, and various objects shown with the oxyhydrogen microscope by How and Company. The large entrance hall was decorated with plants and flowers, and used as a promenade. The two museums of the College were also thrown open. Refreshments were supplied by the steward of the College. The guests were provided with a classified catalogue of the objects exhibited, but they were so numerous that it was impossible for any one to examine more than a small part of the whole. One of the most satisfactory results of the soirée is the great impression produced by it on the foreign scientific men, who appear to have been quite unprepared for, and greatly surprised at, what they saw during the evening.

\section{ON CERTAIN METHODS OF CHEMICAL RESEARCH ${ }^{1}$}

THE lecturer began by describing the simple form of apparatus which he employed many years ago in his researches on the heat evolved in the combination of oxygen, chlorine, bromine, \&c., with other bodies. In every case the bodies to be combined were inclosed in a vessel surrounded with water, and the combination was effected either by the ignition of a fine platinum wire, or where they acted directly upon one another, by the fracture of a glass capsule containing one of the combining bodies, the heat being measured by the rise of temperature of the water. He next referred to the arrangement by which he had been the first to decompose water so as to render visible the hydrogen and oxygen, and to measure their relative volumes by means of atmospheric electricity and of electrical currents from the ordinary machine. For this purpose fine platinum wires were hermetically sealed into fine thermometer tubes, which were then filled with dilute sulphuric acid by withdrawing the air by ebullition. The same current of frictional electricity will decompose the water in almost an indefinite number such couples arranged in a consecutive series. Capillary tubes of this kind may be employed for eudiometric experiments, which would be exceedingly tedious in wide tubes. Thus oxygen gas can at once be absorbed by passing the silent discharge through it while standing I Abstract of a Lecture to the Chemical Society by Dr. Andrews, F.R.S.,
April 28 . Communicated by the author. 